\title{
Federic Ogée et Anthony Strugnell, Diderot and European culture
}

\section{Paola Sosso}

\section{Q OpenEdition \\ 1 Journals}

\section{Edizione digitale}

URL: http://journals.openedition.org/studifrancesi/9221

DOI: 10.4000/studifrancesi.9221

ISSN: 2421-5856

\section{Editore}

Rosenberg \& Sellier

\section{Edizione cartacea}

Data di pubblicazione: 1 juin 2008

Paginazione: 189-190

ISSN: 0039-2944

\section{Notizia bibliografica digitale}

Paola Sosso, «Federic Ogée et Anthony Strugnell, Diderot and European culture», Studi Francesi [Online], 154 (LII | I) | 2008, online dal 30 novembre 2015, consultato il 12 janvier 2021. URL: http:// journals.openedition.org/studifrancesi/9221 ; DOI: https://doi.org/10.4000/studifrancesi.9221

Questo documento è stato generato automaticamente il 12 janvier 2021.

\section{(c) (i) $\odot$}

Studi Francesi è distribuita con Licenza Creative Commons Attribuzione - Non commerciale - Non opere derivate 4.0 Internazionale. 


\title{
Federic Ogée et Anthony Strugnell, Diderot and European culture
}

\author{
Paola Sosso
}

\section{NOTIZIA}

FEDERIC OGÉE et ANTHONY STRUGNELL, Diderot and European culture, Oxford, Voltaire

Foundation, 2006, pp. 245.

1 L'Introduzione, ad opera dei due curatori, mette in luce il ruolo centrale di Diderot nel collegare tra loro e diffondere vari elementi dell'Enlightenment culture: in questo volume il filosofo non è infatti considerato come un autore, ma piuttosto come una figuracardine in grado di uscire da una serie di stereotipi in ambito filosofico, letterario e artistico. Questo elemento è messo in evidenza in modo chiaro dal primo studio di Sriniva ARAVAMUDA (Talking jewels and other oriental seductions, pp. 15-34), incluso nella prima sezione dal titolo "The non European other», che parte dall'analisi de Les bijoux indiscrets per mostrare il valore positivo di alcuni elementi 'non stabili', presentati cioè in modo non univoco dall'autore, quali ad esempio l'approccio etnofilosofico e la geografia politica. Partendo, come Aravamuda, dalla prospettiva di un Diderot capace di confrontarsi con una realtà non europea, Andrew CURRAN esamina alcuni articoli dell'Encyclopédie riguardanti l'Africa e li mette in confronto con la visione di un'umanità libera e lontana dallo schiavismo quale compare in alcune pagine dell'Histoire des deux Indes. (Diderot and the "Encyclopédie"'s construction of the black African, pp. 35-53). Gianluigi GOGGI apre la seconda sezione del volume, «The European experience»: partendo da due manoscritti del fondo Vandeul, ci mostra in quale modo Diderot elaborò un progetto di civilisation della Russia, progetto che egli confrontò con la realtà per correggerlo e migliorarlo. L'approccio del philosophe rifugge da qualsiasi dogmatismo e mostra una coscienza storica matura nel concepire la strada dell'umano progresso come fragile e incerta (Diderot et la Russie: colonisation et civilisation. Projets et expérience directe, pp. 57-76). Colas Duflo s'interroga sull'immagine di Pietro il Grande così come essa è 
rappresentata negli scritti di Diderot, evidenziando un'evoluzione nel giudizio del filosofo che va di pari passo con un mutamento del suo pensiero politico (La statue du bon despote: Diderot et la figure de Pierre le Grand, pp. 77- 86). Girolamo IMBRUGLIA, in Un voyage manqué: Diderot, Grimm et le mythe de Venise (pp. 87-101) ci presenta l'immagine di Venezia nella visione di Grimm e di Diderot. Mentre il primo la considera uno stato dispotico i cui cittadini sono tuttavia felici, il secondo non scorge nel bonheur della città altro che apparenza, e trova nel dibattito su Venezia lo spunto per un'analisi della relazione tra virtù, libertà e felicità. Anthony STRUGNELL ricostruisce la posizione di Diderot nei confronti della storia inglese: la nazione rappresenta ai suoi occhi il paradosso di uno stato che, pur avendo inventato la libertà, la nega ai suoi cittadini (An island race: Diderot's deconstruction of English History, pp. 103-114). Frédéric OGÉE, che apre la sezione intitolata «Translating English thought», si sofferma sul modo originale in cui Diderot, nel clima francese di generale euforia per Richardson, recepì e rielaborò la morale dell'autore inglese (Diderot and Richardson, pp. 117-128). Julie CANDLER HAYES si sofferma sulle riflessioni di Diderot relative alla traduzione (Around 1740: Diderot and the subject of translation, pp. 129-144), mentre Marian HOBSON evidenzia quelli che chiama "patches of incertainty» nella vita di Diderot, considerando la sua carriera come una successione di adesioni a gruppi intellettuali di matrice diversa (nel gruppo degli encyclopédistes, con Raynal nella redazione della Histoire des deux Indes...; Diderot, the European underground and English radical thought: filling out the gaps, pp. 145-157). John o'NEAL chiude la sezione analizzando Diderot and the Enlightenment's poetics of confusion in the "Lettre sur les aveugles" (pp. 159-169). Nell'ultima sezione, "Constructing "Diderot"», si trovano tre studi: nel primo, Nicholas CRONK mostra in quale modo sia possibile ritrovare le tracce del pensiero di Hobbes e Hume in Jacques le fataliste, anche se Diderot non li cita in modo diretto (Hobbes and Hume: determinig voices in "Jacques le fataliste et son maître", pp. 173-182). L'intervento di Daniel BREWER ricostruisce invece la figura di Diderot così come è stata plasmata nel diciannovesimo secolo a partire dalle commemorazioni della Terza Repubblica fino ai testi di storia letteraria e ai manuali scolastici (Diderot and the culture of belatedness, pp. 183-196). In ultimo, Jean-Claude BOURDIN in Comment (ne pas) hériter de Diderot? (pp. 197-223) sottolinea gli elementi di modernità di una filosofia vicina al mondo di oggi nel suo rifiuto di qualsiasi modello di conoscenza universale ed eccessivamente sistematizzato. Il volume è completato dalla Bibliografia e dall'Indice dei nomi. 